\title{
EFISIENSI STRUKTUR ALAMI, ANTARA BENTUK DAN SISTEM STRUKTUR
}

\author{
MAER, Bisatya W. \\ Program Studi Arsitektur, Universitas Kristen Petra \\ Email: mbm@peter.peptra.ac.id
}

\begin{abstract}
ABSTRAK
Tulisan ini membahas desain bangunan yang bertolak dari prinsip efisiensi struktural benda-benda/mahluk-mahluk alami. Untuk mempelajari lebih dalam bagaimana prinsip efisiensi tersebut diterapkan dalam desain, tiga karya Frei Otto dipilih sebagai studi kasus. Karya-karya tersebut adalah: recumbent container yang diinspirasi oleh tetes air raksa; bell tower gereja Protestan di Berlin-Schonow yang diinspirasi oleh batang Cholla cactus; dan kolom bercabang yang diinpirasi oleh pohon. Tiap kasus ini dikaji untuk menggali apakah efisiensi struktural dari benda-benda tersebut dimanfaatkan Otto dari segi 'model/sistem struktur'nya atau dari segi ‘keunikan bentuk’nya. Tingkat efisiensi struktural dari tiap kasus juga akan ditelaah. Desain recumbent container menerapkan model/sistem struktur 'membran' tetes air raksa. Model/sistem struktur Cholla cactus tidak diterapkan apa adanya, melainkan dengan menggunakan prinsip sistem struktur perimeter yang dikembangkan ke dalam bentuk dan model/sistem struktur yang berbeda. Pada kasus struktur pohon, bentuk dan susunan cabang pohon digunakan sebagai dasar untuk membentuk struktur kolom bercabang dengan model/sistem struktur yang berbeda. Melalui kajian struktural ini, ketiga bangunan tersebut termasuk efisien.
\end{abstract}

Kata kunci: Efisiensi-struktural, bentuk, model/sistem struktur.

\begin{abstract}
This paper discusses building design based on structural efficiency principles of natural objects and creatures. To investigate further about how the efficiency principle is implemented in design, three of Frei Otto's projects are chosen as case studies. Otto's project chosen for this study are: the recumbent container which was inspired by a mercury drop; the bell tower of a Protestant Church in Berlin-Schonow which was inspired by Cholla cactus stem; and a branched column inspired by trees. Each of this case is analyzed to find out whether the structural efficiency of these objects are used by Otto from its 'structural model/system' perspective or from the uniqueness of its form. The structural efficiency level of each case is also analyzed. The design of the recumbent container implemented the structural model/ system of the mercury drop's membrane. The Cholla cactus's structural model/ system was not implemented as it is but the perimeter structural principal system was developed into different form and structural model/ system. In the last case, the tree's shape and branches formation were being used to create the branched column's structure with different structural model/ system. Both three buildings are structurally efficient.
\end{abstract}

Keywords: Structural efficiency, form, structural model/system.

\section{PENDAHULUAN}

Dalam beberapa literatur diungkapkan bahwa benda-benda dan mahluk-mahluk alami mempunyai struktur yang efisien, sehingga banyak ahli struktur yang memanfaatkannya sebagai inspirasi untuk menemukan sistem struktur bangunan yang efisien. Falmur Ahmeti (2007) mengutip Winfried Nerdinger mengatakan bahwa Frei Otto melakukan banyak studi pencarian-bentuk (form-finding) proses alam, dan sebagai arsitek dia memanfaatkan proses-proses tersebut untuk mengembangkan dan membangun banyak struktur bangunan. Prinsip Frei Otto adalah mengurangi berat massa dan dengan demikian menghasilkan efisiensi struktural. Karya-karya Frei
Otto yang terinspirasi benda-benda dan mahlukmahluk alami selain efisien, juga menampilkan citra yang unik dan estetis. Hal ini menunjukkan bahwa efisiensi struktural bisa mempengaruhi bentuk dan estetika bangunan, seperti yang dikatakan oleh Seymour Howard (1966), dan Angus Macdonald (2001), Sandaker (2008) dengan cara penyampaian berbeda-beda, yang dibahas dalam pembahasan efisiensi dan bentuk struktural.

Disisi lain beberapa arsitek memanfaatkan benda atau mahluk alami pertama-tama bukan dari efisiensi strukturalnya, tapi sebagai simbol atau metafora tertentu untuk menampilkan citra arsitektural, walaupun mungkin saja strukturnya juga efisien seperti yang diungkapkan oleh Hugh Aldersey- 
Williams (2003) dalam 'Zoomorphic, new animal architecture' dan Joseph Lim (2009) dalam 'Biostructural analogues in architecture'. Wiliams memberikan contoh beberapa karya Santiago Calatrava, antara lain Lyon Airport Station di Perancis.

Penulis tertarik mendalami karya-karya desain yang bertolak dari pertimbangan efisiensi struktural benda-benda/mahluk-mahluk alami untuk menghasilkan bentuk bangunan. Untuk itu, dalam tulisan ini dipilih karya-karya dan pemikiran Frei Otto, dimana karyanya bukan dihasilkan dari metafora bentuk, melainkan dari pencarian efisiensi struktural bendabenda/mahluk-mahluk alami. Dalam tulisan ini akan dikaji apakah efisiensi struktural tersebut dimanfaatkan oleh Frei Otto dari segi 'model/sistem struktur' nya atau dari segi keunikan 'bentuk'nya. Selain itu akan dikaji juga tingkat efisiensi struktural tiap kasus yang diambil dari tiga studi kasus karya Frei Otto, yaitu: recumbent container, bell tower gereja Protestan di Berlin-schonow, dan kolom bercabang/kolom berbentuk pohon.

\section{EFISIENSI}

Sandaker (2008) membedakan efisiensi mekanikal dalam dua isu, yaitu: 1) efisiensi struktural, dan 2) efisiensi teknologi. Efisiensi struktural adalah ratio antara 'kapasitas dukung beban' dibanding dengan 'jumlah material struktural'. Apabila ratio tersebut besar maka strukturnya efisien. Efisiensi teknologi berhubungan dengan sistem dan proses pembangunan, menurut Sandaker (2008) efisiensi struktural berbanding terbalik dengan efisiensi teknologi, struktur yang semakin efisien secara struktural akan semakin tidak efisien secara teknologi (Gambar 1). Macdonald (2001) memberikan contoh bahwa struktur form-active tarik misalnya struktur membran, adalah struktur yang paling efisien secara struktural dimana penggunaan materialnya minimal untuk kapasitas dukung/bentang yang sangat besar, namun dari segi teknologi sangat rumit, misalnya untuk menentukan bentuk geometrinya dengan tepat tidak mudah, sehingga sulit dibentuk secara tepat dalam pembangunannya. Oleh karena itu untuk mempertajam pembahasan, tulisan ini hanya akan difokuskan pada pembahasan efisiensi struktural saja dan tidak disinggung efisiesi teknologi.

Ada dua hal yang mempengaruhi efisiensi struktural, yaitu: 1) jenis gaya yang bekerja didalam struktur. Gaya-gaya yang bekerja di dalam struktur adalah, gaya aksial tarik, gaya aksial tekan, gaya geser, momen lentur dan momen torsi. 2) kepadatan penampang struktural, apakah penampangnya padat/ masif atau penampangnya berongga/kosong. Menurut Sandaker (2008), struktur yang menerima gaya aksial saja lebih efisien daripada struktur yang menerima momen lentur. Struktur yang menerima gaya aksial tekan lebih efisien apabila strukturnya tidak terlalu langsing (kurus dan panjang), karena struktur langsing mengalami tekuk sebelum kapasitas kekuatannya

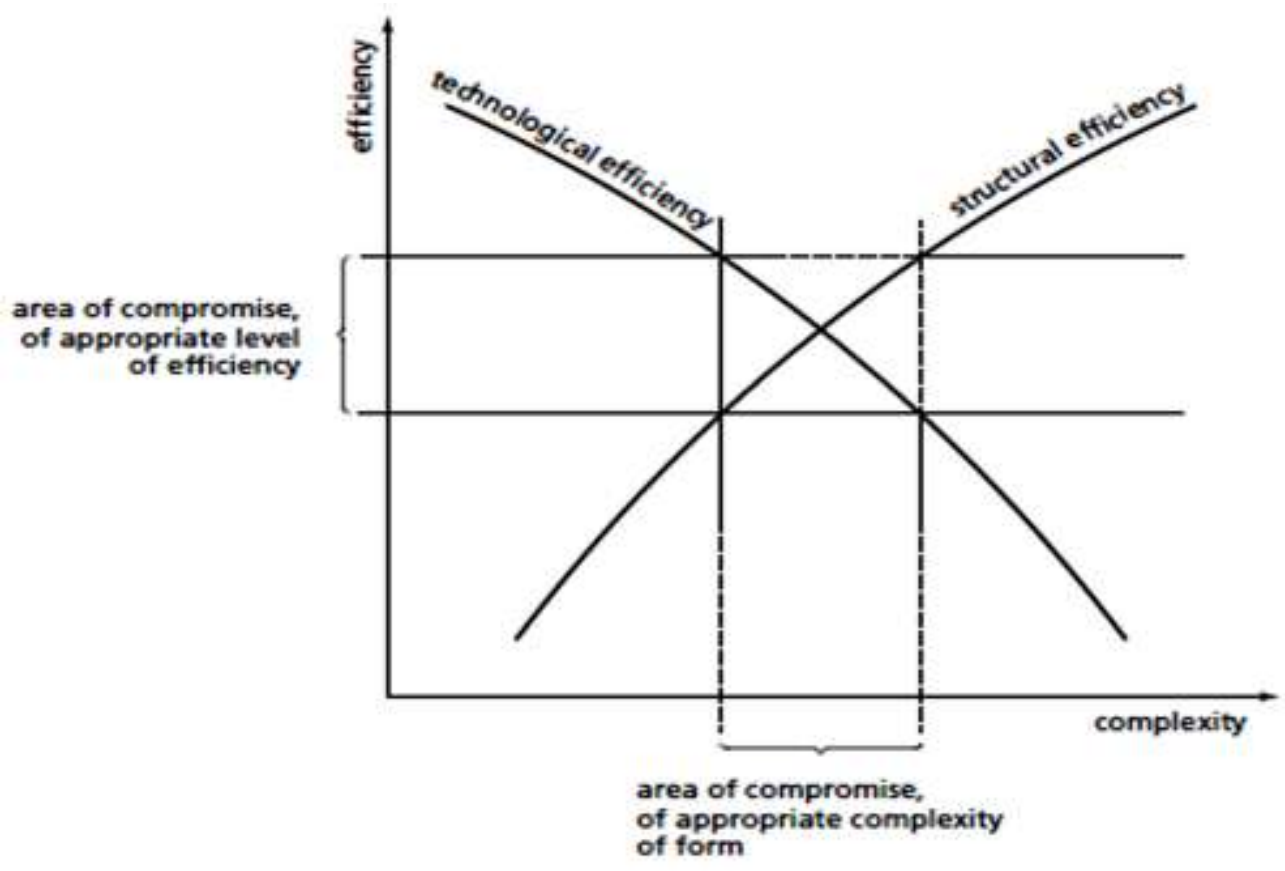

Sumber: Sandaker, 2008

Gambar 1. Diagram Efisiensi Struktural vs Efisiensi Teknologi 
dicapai, sehingga kapasitas kekuatan struktur tersebut tidak termanfaatkan secara maksimal. Ditinjau dari kepadatan penampang-nya, struktur dengan penampang yang berongga lebih efisien dibandingkan dengan struktur dengan penampang padat, khususnya untuk struktur yang menerima momen lentur. Frei Otto membandingkan penampang berongga dengan sayap burung (Gambar 2) yang di dalamnya berongga sehingga sangat ringan tapi kuat (Roland, 1970).

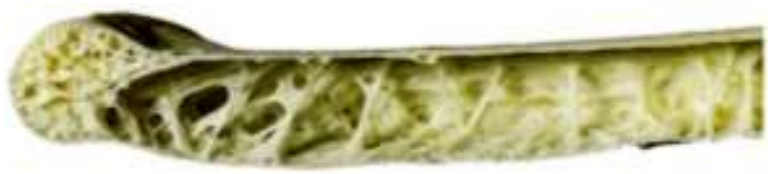

Sumber:

http://www.google.co.id/imgres?q=bird+bone+structure \& $\mathrm{um}=1 \& \mathrm{hl}=\mathrm{id} \& \mathrm{sa}=\mathrm{N} \& \mathrm{tbo}=\mathrm{d} \& \mathrm{biw}=791 \& \mathrm{bih}=517 \& \mathrm{tbm}=\mathrm{isch} \& \mathrm{tbn}$ id=XBh-96iwxQdOWM:\&imgrefurl=http://www.sciencepartners. info/\%3Fpage_id\%3D691\&docid=E1TETMGG-cfuWM\&imgurl =http://www.sciencepartners.info/wp-content/uploads/2012/08/ crosssec.jpg\&w=464\&h=298\&ei=-ea2UMaGFYHyrQfq oH4DQ\&zoom=1\&iact=rc\&dur=626\&sig=115913550354497061 404\&page $=2 \&$ tbnh $=121 \&$ tbnw $=188 \&$ start $=11 \&$ ndsp $=18 \&$ ved $=1 \mathrm{t}$ :429,r:22,s:0,i:151\&tx=68\&ty $=63$

Gambar 2. Tulang Burung

Agar struktur dengan penampang berongga dapat dikonstruksikan dengan mudah, dilakukan penyederhanaan bentuk geometri seperti segitiga, segiempat, segienam dan sebagainya, membentuk rangka batang (plane truss), space truss, vierendeel, hexagonal frame dan sebagainya. Struktur dengan bentuk unit segitiga (truss) lebih efisien dibandingkan dengan bentuk unit segiempat/vierendeel, segienam (hexagonal frame) dan lain-lain. Hal ini disebabkan bentuk segitiga merupakan bentuk geometri yang stabil, sehingga join pertemuan antar batang dapat bersifat sendi. Dengan demikian pada batang-batang truss hanya bekerja gaya aksial saja, baik tekan atau tarik, sedangkan pada batang-batang vierendeell hexagonal frame bentuk geometri per unitnya tidak stabil, sehingga join pertemuan antar batang harus join momen dan di dalam batang-batangnya bekerja momen, gaya geser dan gaya aksial.

\section{EFISIENSI DAN BENTUK STRUKTURAL}

Efisiensi struktural sangat terkait dengan bentuk struktural, seperti yang dikatakan Howard (1966) bahwa pencarian minimal structure (struktur dengan penggunaan material minimal) dapat menghasilkan bentuk bangunan yang sangat menarik. Macdonald (2001) membahasnya dalam hubungan antara tampilan arsitektur dengan struktur, yaitu 'struktur sebagai arsitektur' dan 'struktur sebagai ornamen'. Dalam 'struktur sebagai arsitektur', efisiensi struktural memang dibutuhkan secara teknis, bentuk dan citra arsitektural terjadi karena bentuk struktur yang dihasilkan dari efisiensi struktural. Dalam salah satu kategori 'struktur sebagai ornamen' (Macdonald mengkategorikan struktur sebagai ornamen dalam 3 kategori), arsitek dengan sengaja mengkondisikan model struktur (karena alasan citra) agar dapat dicari bentuk struktur berdasarkan efisiensi struktural.

Sandaker (2008) membagi bentuk struktural dalam dua tingkatan bentuk, yaitu: global-form (bentuk keseluruhan) dan local-form (bentuk elemen/ komponen/detail struktural). Pada tingkatan globalform, efisiensi struktural dihasilkan oleh struktur form-active. Pada tingkatan local-form efisiensi struktural diperoleh melalui pembentukan konfigurasi penampang melintang maupun penampang memanjang komponen struktural. Penampang melintang komponen struktural dibentuk agar menghasilkan momen inersia (I) yang sebesar mungkin dengan jumlah material seminimal mungkin. Untuk struktur yang menerima momen, efisiensi struktural dapat dilakukan dengan menempatkan material terbanyak di sisi paling luar dari penampang komponen struktural agar diperoleh I yang maksimal. Hal tersebut nyata dalam struktur berongga dimana materialmaterial penahan gaya tarik dan tekan berada di sisi paling luar. Untuk mendapatkan efisiensi struktural lebih lanjut, dilakukan penyesuaian dimensi penampang melintang komponen struktur dengan besarnya tegangan lentur yang bekerja sehingga penampang memanjangnya membentuk konfigurasi yang sesuai dengan diagram momen yang bekerja.

\section{STRUKTUR FORM-ACTIVE, STRUKTUR NON FORM-ACTIVE, STRUKTUR SEMI FORM-ACTIVE}

Bentuk struktur form-active dalam keadaan ideal identik dengan garis alur tegangan, oleh karena itu bentuk struktur form-active merupakan garis gaya alami. Di dalam struktur form-active tersebut hanya bekerja gaya aksial saja, tekan atau tarik. Garis gaya alami struktur form-active tekan adalah garis funikular tekan, pada struktur form-active tarik adalah garis funikular tarik (Heino Engel, 1977). Geometri lengkung funikular terbentuk oleh sistem pembebanan, contohnya kabel yang terbentang bentuknya melengkung kebawah dengan bentuk geometri catenary akibat beratnya sendiri (Gambar 3), apabila kabel diberi beban terpusat yang besar ditengah bentang, maka bentuk funikularnya berubah menjadi poligon segitiga. 
Pengertian tersebut dapat dimanfaatkan untuk memahami bentuk funikular tekan dengan material kaku seperti beton atau baja, yaitu dengan meninjau bentuk yang berbalik cermin dengan lengkung funikular kabel (Gambar 4).

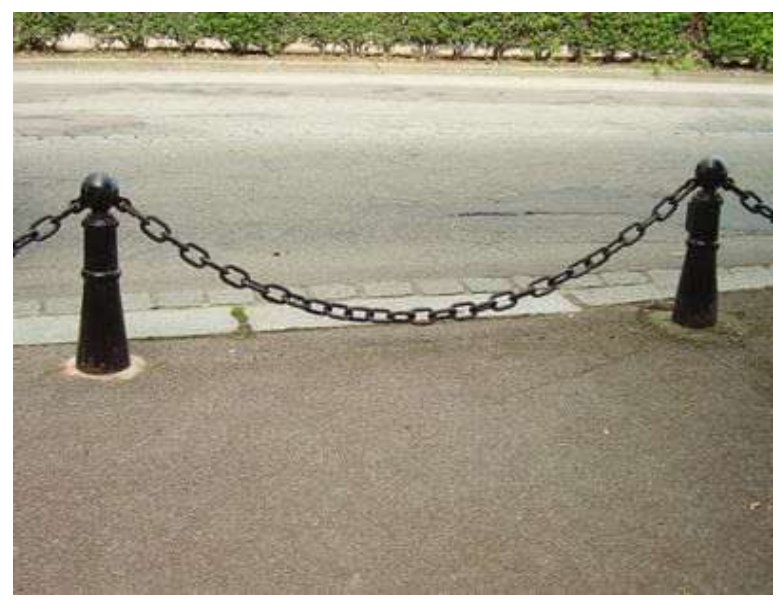

Sumber:

http:/www.google.co.id/imgres?start=27\&num=10\&um=1\&hl= id\&client=firefox-a\&tbo=d\&rls=org.mozilla:en-US:official \& channel=np\&biw $=791 \&$ bih $=517 \&$ tbm $=$ isch $\&$ tbnid $=q J P q 05 P V A$ BXQgM:\&imgrefurl=http://masonrydesign.blogspot.com/2012/02/ catenary-domes.html\&docid=7YVorWICcWqXQM

\&imgurl=http://mathforum.org/mathimages/imgUpload/thumb/Cat enary3.jpg/400px-Catenary3.jpg\&w=400\&h=300\&ei=EDO8UOn CLMOqrAeXr4DQDw\&zoom=1\&iact=rc\&dur=429\&sig=11591 $3550354497061404 \&$ sqi $=2 \&$ page $=3 \&$ tbnh $=139 \&$ tbnw $=206 \&$ nds $\mathrm{p}=16 \&$ ved=1t:429,r:42,s:0,i:70\&tx=39\&ty=109

Gambar 3. Bentuk Lengkung Funikular Tarik

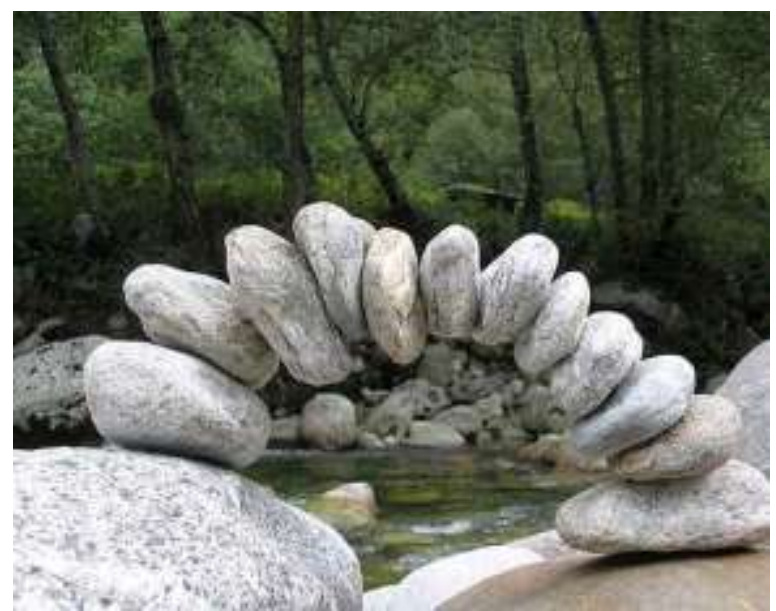

Sumber:

http://www.google.co.id/imgres?q=arch+stone\&um=1\&hl=id\&tbo= $\mathrm{d} \& \mathrm{biw}=853 \& \mathrm{bih}=585 \& \mathrm{tbm}=$ isch\&tbnid=RjTYRq7ZDuY_TM:\&imgrefur l=http://www.pehub.com/21113/stone-arch-building-third-fund/\&docid=8N4iCzGjevoeM\&imgurl=http://c276161.r61.cf1.rackcdn.com/wp-content/ uploads//stone-arch-swiss-river1.jpg\&w=500\&h=375\&ei=zhntUNCJMsb NkgW33ICACw\&zoom=1\&iact=rc\&dur=340\&sig=115913550354497061 404\&page=1\&tbnh=149\&tbnw=206\&start=0\&ndsp=13\&ved=1t:429,r:6,s: $0, \mathrm{i}: 99 \& \mathrm{tx}=112 \&$ ty $=92$

Gambar 4. Susunan Batu dengan Bentuk Funikular Tekan
Perbedaan form-active tekan dan tarik terletak pada sifat materialnya, material tarik yang fleksibel selalu menyesuaikan bentuknya dengan sistem pembebanannya, sehingga strukturnya selalu formactive, sedangkan material tekan yang bersifat kaku tidak bisa menyesuaikan bentuknya dengan sistem pembebanannya, maka apabila ada perbedaan antara bentuk struktural dengan sistem pembebanannya, di dalam struktur tersebut disamping bekerja gaya tekan juga bekerja momen.

Selain struktur form-active, terdapat struktur non form-active yaitu struktur yang menerima momen lentur, contohnya balok lantai yang terbentang horisontal, dan struktur semi form-active yaitu struktur yang menerima momen lentur dan gaya aksial, contohnya balok atap yang terbentang membentuk sudut terhadap garis horisontal (miring).

\section{KERANGKA PEMBAHASAN}

Dalam pembahasan selanjutnya akan dilakukan perbandingan secara kualitatif antara 'model struktur karya Frei Otto' dengan'model struktur benda/mahluk alami' yang bersangkutan. Dari perbandingan tesebut dapat disimpulkan seberapa jauh persamaan dan perbedaan kedua model yang dibandingkan. Apabila ternyata kedua model struktur tersebut sama, maka dapat disimpulkan bahwa efisiensi struktural berasal dari 'sistem/model struktur'nya, sebaliknya apabila model strukturnya berbeda, maka dapat disimpulkan bahwa 'bentuk' benda/mahluk alami dimanfaatkan sebagai inspirasi desain, sedangkan efisiensinya didapat dari sistem yang berbeda.

Penilaian tentang efisiensi struktural berdasarkan parameter kualitatif yang didasarkan pada pemahaman hubungan antara bentuk dan efisiensi yang telah dibahas diatas. Struktur efisien apabila:

- Strukturnya form-active.

- Strukturnya semi form-active yang didominasi gaya aksial. Apabila gaya tersebut aksial tekan, panjang tekuknya relatif pendek.

- Strukturnya non form-active. Apabila penampang strukturnya semakin berongga semakin efisien.

\section{STUDI KASUS}

\section{Recumbent Container}

Recumbent container adalah tempat penyimpanan cairan gagasan Frei Otto, yang bentuknya diinspirasi oleh bentuk tetes air raksa. Tetes air raksa berbentuk seperti bola yang proporsinya melebar mendekati elipsoida, tapi karena gravitasi maka lengkung dibagian bawah lebih tajam dibandingkan bagian atas (Gambar 5a). 


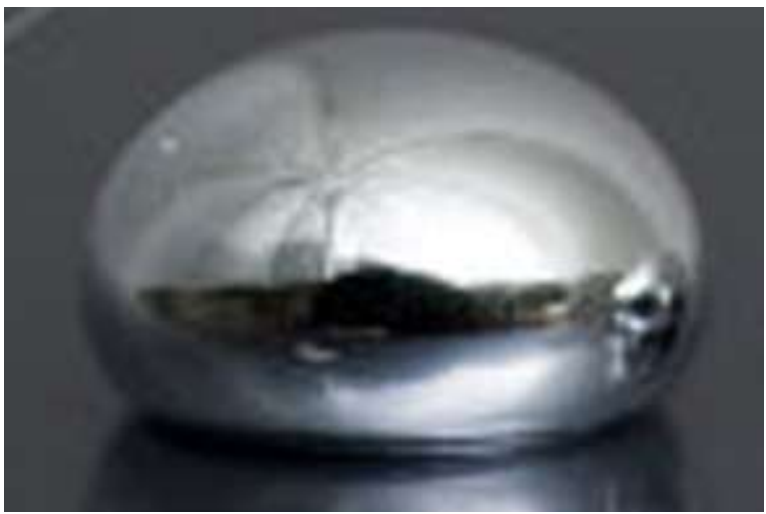

Sumber:

http://www.google.co.id/imgres?q=mercury+drops\&start=46\&nu $\mathrm{m}=10 \& u m=1 \& \mathrm{hl}=\mathrm{id} \& \mathrm{tbo}=\mathrm{d} \& \mathrm{biw}=1024 \& \mathrm{bih}=677 \& \mathrm{tbm}=\mathrm{isch} \& \mathrm{t}$ bnid=v9ZxfaTFDJJn_M:\&imgrefurl=http://www.shutterstock.com /pic-37569550/stock-photo-shiny-mercury-drops-on-a-pit-blackbackground.html\&docid=g3Abg85la-

08eM\&imgurl=http://image.shutterstock.com/display_pic_with_lo go/104335/104335,1253717002,5/stock-photo-shiny-mercurydrops-on-a-pit-black-background-

37569550.jpg\&w=450\&h=320\&ei=RTC-

UMWMA4eNrgf2ooHADw\&zoom=1\&iact=rc\&dur=201\&sig=1 $04466141129297738101 \&$ sqi $=2 \&$ page $=3 \&$ tbnh $=136 \&$ tbnw $=194$ \&ndsp=26\&ved=1t:429,r:58,s:0,i:118\&tx=174\&ty=86

Gambar 5a. Tetes air raksa

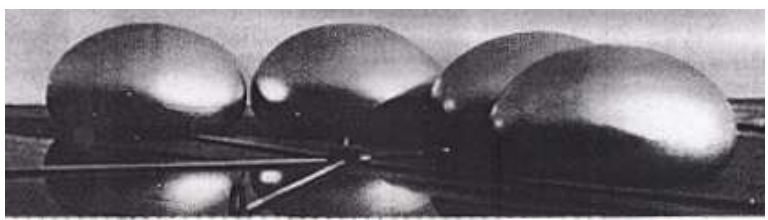

Sumber: Roland, 1970

Gambar 5b. Model studi recumbent container dengan material fleksibel karya Frei Otto.

Dalam pemahaman mekanika fluida, pada bidang temu antara zat cair dan gas timbul gaya-gaya dipermukaan cairan yang menyebabkan permukaan tersebut berperilaku seakan merupakan suatu 'kulit'/ 'membran', dan bentuk tetes air raksa tersebut dapat bertahan karena gaya kohesi permukaan cenderung mengikat seluruh molekul (Munson, 2003). Menurut Roland (1970), tegangan tarik di permukaan 'membran' tersebut sama besar disetiap titik. Prinsip ini berlaku juga untuk container, sehingga sangat menguntungkan apabila dikonstruksikan dengan membran fleksibel karena pada saat container telah diisi penuh dengan cairan, di seluruh permukaan membran tersebut bekerja tegangan-tegangan tarik murni yang sama besar. Dengan prinsip tersebut, Frei Otto memilih material struktur container dari membran yang fleksibel dalam eksperimennya (Gambar 5b). Pada saat belum terisi cairan, container tersebut rentan terhadap gaya-gaya eksternal, maka didalam container tersebut diberikan tekanan udara terlebih dahulu, kemudian cairan dimasukkan sampai penuh (Gambar 6).
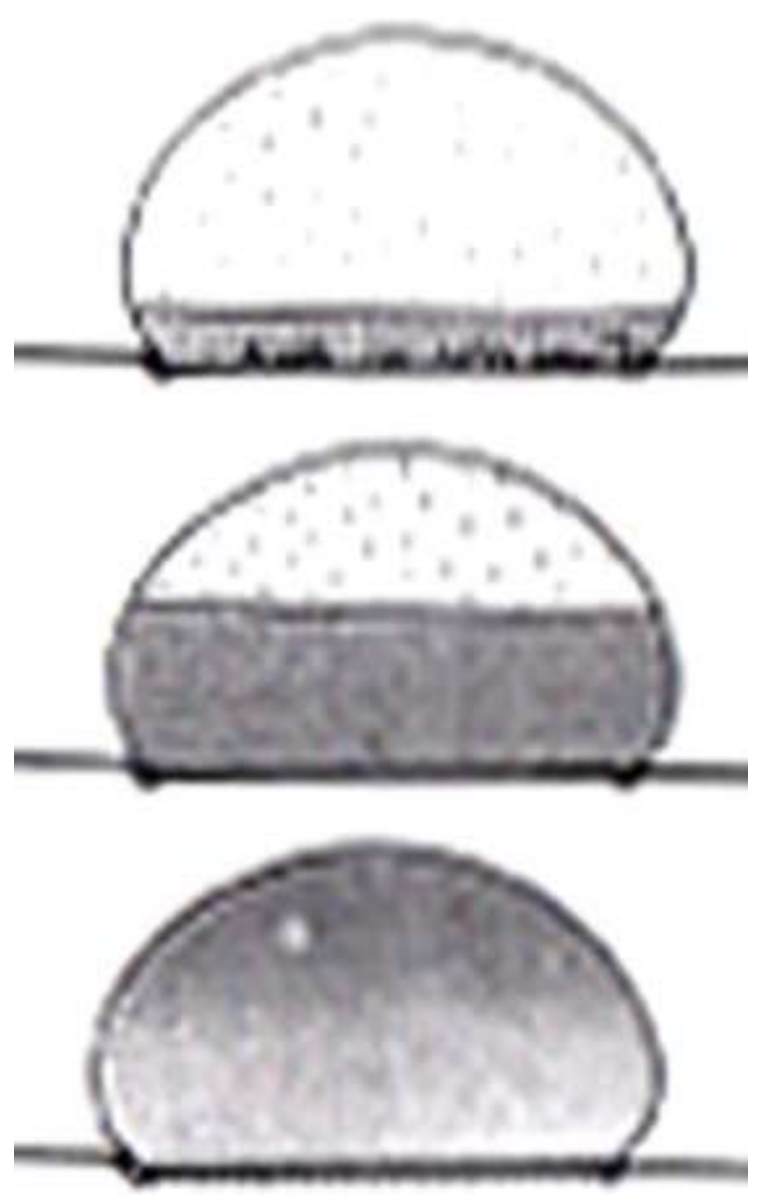

Gambar 6. Proses pembentukan recumbent container. Roland, 1970

\section{Diskusi:}

Uraian diatas menunjukkan bahwa membran container dibentuk berdasarkan pengaruh tekanan dari dalam. Pada awalnya diisikan tekanan udara untuk memberikan stabilitas pada struktur tersebut, sehingga container cenderung berbentuk bola, setelah itu cairan yang diisikan merubah geometri bola tersebut menjadi seperti geometri air raksa. Bentuk struktur container tersebut serasi dengan pembebanannya dan pada kulitnya yang fleksibel hanya bekerja tegangan tarik, karena itu strukturnya adalah struktur form-active, yang termasuk struktur paling efisien.

Maka dapat disimpulkan bahwa efisiensi struktur container dalam kasus ini dipicu oleh 'model/ sistem' struktur tetes air raksa, tidak oleh bentuknya. Struktur recumbent container merupakan struktur form-active, maka struktur tersebut efisien. Ketajaman intiusi dan kepakaran dibidang struktur ringan ditunjukkan oleh Frei Otto dengan menemukan pemicu ide dari benda alami yang sangat kecil untuk struktur bangunan yang sangat besar dan berat. 


\section{Bell Tower Gereja Protestan di Berlin-Schonow}

Model struktur dari alam yang dipelajari oleh Frei Otto dan berhubungan dengan rancangan bell tower, adalah tanaman Cholla cactus yang tumbuh di padang gurun daerah baratdaya Amerika Serikat. Batang Cholla cactus (selanjutnya disebut Cholla cactus saja) berbentuk silinder yang dindingnya terbentuk dari rangka perimeter. Rangka perimeter tersebut merupakan rangkaian serat yang membentuk pola grid diagonal (Gambar 7a, 7b) yang sangat efisien, dimana kekuatan/kekakuan tekuk maksimal Cholla cactus dicapai dengan jumlah material yang minimal (Roland, 1970). Dengan pola grid berbentuk segiempat diagonal, maka join antar serat-serat Cholla cactus bersifat kaku (join momen), untuk dapat mempertahankan bentuk jajarangenjang tersebut. Uraian tersebut menunjukkan bahwa Cholla cactus merupakan struktur kantilever yang penampang melintangnya berongga/kosong dan dindingnya merupakan bidang perimeter yang juga berongga. Prinsip tersebut oleh Frei Otto dikembangkan dalam struktur vierendeel yang salah satunya diterapkan pada bangunan bell tower. Struktur vierendeel tersebut bukan temuan Frei Otto, struktur tersebut ditemukan oleh Arthur Virendeel tahun 1895 yang terkenal dengan vierendeel bridgenya (http://en. wikipedia.org/wiki/Arthur_Vierendeel, 08 Jan 2012). Kalau Arthur Virendeel menggunakan struktur vierendeel untuk jembatan, Frei Otto menerapkan-nya sebagai struktur kantilever vertikal pada bangunan bell tower.

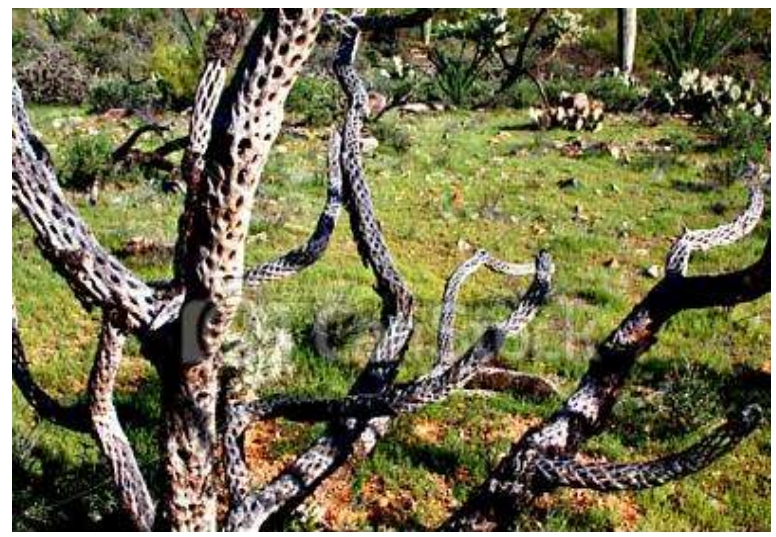

Sumber:

http://www.google.com/imgres?hl=en\&client=firefox-a\&hs=woY $\& s a=X \&$ tbo=d\&rls=org.mozilla:en-US:official\&channel= np\&biw=1187\&bih=776\&tbm=isch\&tbnid=g5DImkPvRt9POM: \&imgrefurl=http://www.canstockphoto.com/cholla-bones3552868.html\&docid=O-1nZ6abcgGJEM\&imgurl=http://ec. comps.canstockphoto.com/can-stock-photo_csp3552868. jpg\&w=400\&h=280\&ei=rlnRUI_JEcWPrgfFp4HoAQ\&zoom=1 \&iact=hc\&vpx=796\&vpy=235\&dur $=80 \&$ hovh $=188 \&$ hovw $=268$ $\& \mathrm{t}=79 \& \mathrm{ty}=93 \& \mathrm{sig}=104860544904810071713 \&$ page $=3 \& \mathrm{tbnh}=$ $135 \&$ tbnw $=187 \&$ start $=61 \&$ ndsp= $35 \& v e d=1 \mathrm{t}: 429, \mathrm{r}: 94, \mathrm{~s}: 0, \mathrm{i}: 378$

Gambar 7a. Cholla cactus di Alam

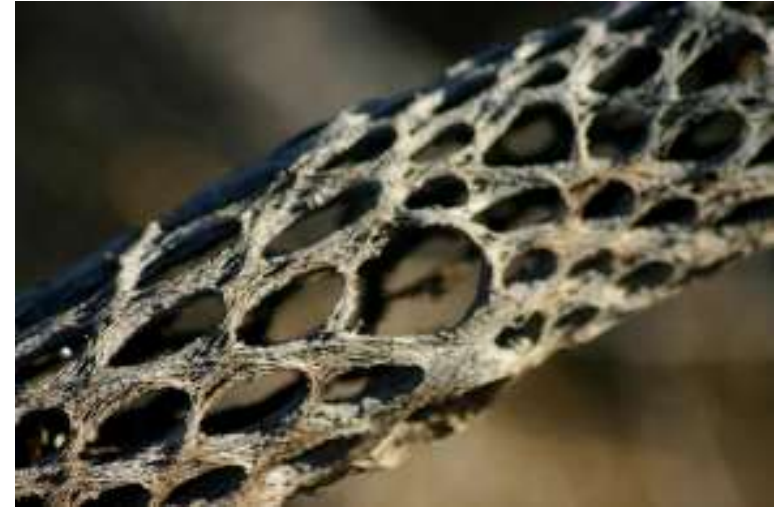

Sumber:

http://www.google.com/imgres?hl=en\&client=firefox-a\&hs=woY $\&$ sa $=X \&$ tbo $=$ d\&rls=org.mozilla:en-US:official\&channel=np\&biw $=1187 \& b i h=776 \& t b m=$ isch\&tbnid=Qsz5q4pg9_fH8M:\&imgrefu rl=http://oneshotleadstoanother.blogspot.com/2011/11/chollacactus-skeleton.html\&docid=OZ3Zo4nRcs8aIM\&imgurl=http:// 1.bp.blogspot.com/-RSZkQ9RKMzE/TpnKnsqyeWI/AAAAA AAAQm0/ZEDkpH6grdQ/s1600/Walk\%252Baround\%252BDes ert $\% 252$ BGardens $\% 252 B 06 . J P G \& w=1024 \& h=683 \&$ ei $=$ rlnRUI J EcWPrgfFp4HoAQ\&zoom=1\&iact=hc\&vpx=777\&vpy=292\&du $\mathrm{r}=3134 \&$ hovh $=183 \&$ hovw $=275 \& \mathrm{tx}=168 \&$ ty $=116 \& \mathrm{sig}=1048605$ 44904810071713\&page $=1 \&$ tbnh $=141 \&$ tbnw $=205 \&$ start $=0$ \&ndsp $=27 \&$ ved $=1 \mathrm{t}: 429, \mathrm{r}: 12, \mathrm{~s}: 0, \mathrm{i}: 126$

Gambar 7b. Detail Batang Cholla Cactus, Rangka Perimeter

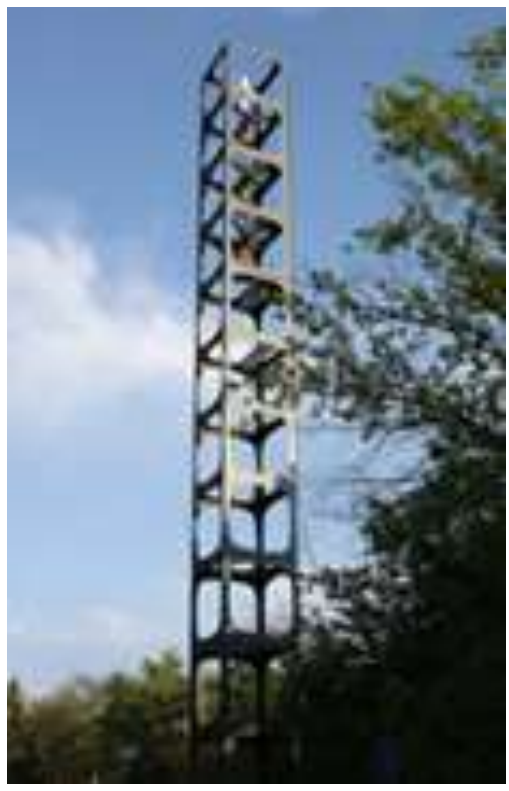

Sumber:

http://www.google.co.id/imgres?num=10\&um=1\&hl=id\&client=fi refox-a\&rls=org.mozilla:en-

US:official\&channel=np\&biw=791\&bih=517\&tbm=isch\&tbnid= 9B63J4tCRImN8M:\&imgrefurl=http://www.freiottoarchitekturmuseum.de/PROJEKTE/projekt45.htm\&docid=pbkzqk VPKHz6IM\&imgurl=http://www.freiotto-

architekturmuseum.de/PROJEKTE/46.jpg \&w=250\&h=421\&ei=q 8alUKGyJ6XiQeG9IHQCQ\&zoom=1\&iact=rc\&dur=515\&sig=1 $15913550354497061404 \&$ sqi $=2 \&$ page $=2 \&$ tbnh $=142 \&$ tbnw $=83 \&$ start=8\&ndsp=14\&ved=1t:429,r:9,s:0,i:89\&tx=31\&ty=53

Gambar 8. Bell Tower Gereja Protestan di Berlin-Schonow 
Struktur bell tower memikul 3 buah lonceng dengan berat masing-masing $290 \mathrm{~kg}, 429 \mathrm{~kg}$ dan 595 $\mathrm{kg}$ (gambar 8). Bell tower tersebut menerima beban dinamik (dominan lateral) pada saat lonceng bergoyang dan berdentang. Dimensi tiap unit vierendeel berukuran $2 \mathrm{~m} \times 2 \mathrm{~m} \times 2 \mathrm{~m}$ dengan tinggi keseluruhan $24 \mathrm{~m}$. Batang-batang vierendeel dibuat dari pelat baja dengan ketebalan bervariasi secara gradual $10 \mathrm{~mm}$ di puncak, dan $50 \mathrm{~mm}$ di dasar.

Diskusi:

Model struktur bell tower dan model struktur Cholla cactus memiliki persamaan dan perbedaan. Struktur bell tower dan Cholla cactus masing-masing adalah struktur kantilever yang terbentuk dari rangka pemikul momen dengan grid segiempat berulang, bedanya pola grid bell tower adalah ortogonal, sedangkan pola grid Cholla cactus adalah diagonal. Kerapatan batang-batang bell tower sangat renggang dibandingkan kerapatan serat-serat diagonal Cholla cactus. Model struktur bell tower adalah kantilever vertikal berbentuk prisma segiempat, yang keempat sisi prisma tersebut dibentuk oleh struktur vierendeel dengan 4 buah kolom (= batang vertikal vierendeel) di keempat pojok/sudutnya (Gambar 9). Model struktur Cholla cactus adalah kantilever berbentuk silinder (tabung) yang dindingnya terbentuk dari rangka pemikul momen dengan grid diagonal yang rapat (Gambar 10).

Dengan perbedaan tersebut, maka kinerja kedua sistem tidak sama. Dalam struktur bell tower yang bekerja terhadap gaya lateral yang bekerja arah sumbu $x$ atau sumbu y yang sentris dan simetris adalah rangka vierendeel sejajar arah gaya saja (Gambar 11a). Apabila gaya lateral arah sumbu x atau sumbu y posisinya eksentris, atau arah gaya membentuk sudut terhadap sumbu $\mathrm{x}$ dan $\mathrm{y}$, baru keempat rangka vierendeel bekerja semua (Gambar 11b).

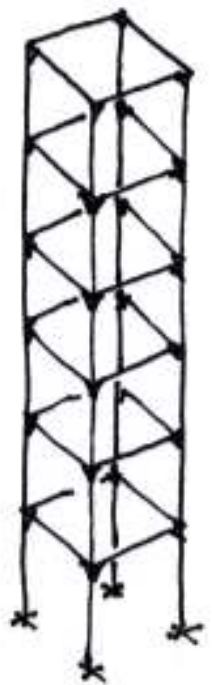

Gambar 9. Model Struktur Bell Tower

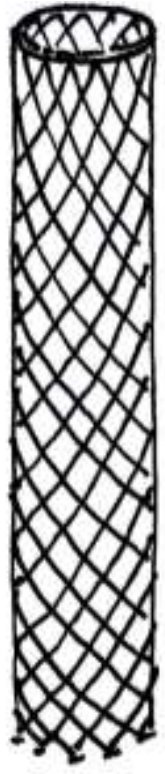

Gambar 10. Model Struktur Cholla cactus

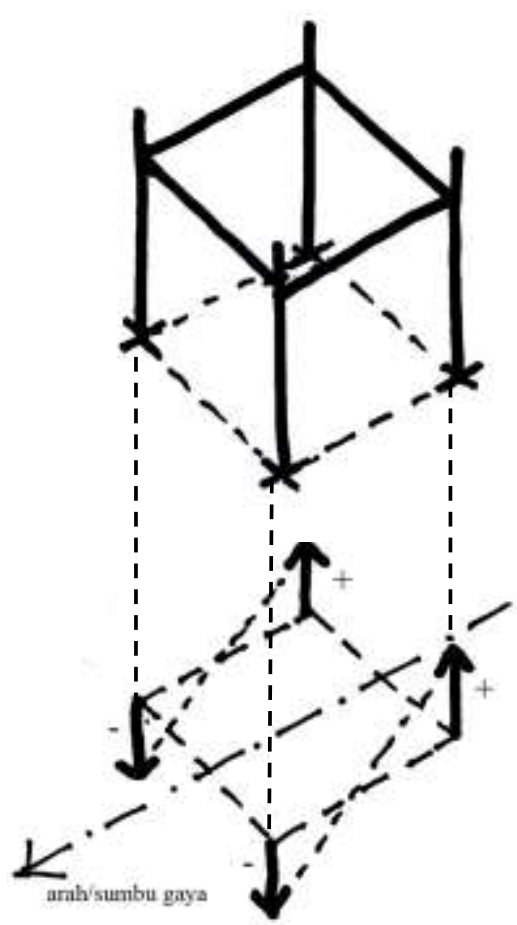

Gambar 11a. Distribusi gaya aksial pada batang vertikal vierendeel terhadap gaya lateral arah sb $\mathrm{x}$

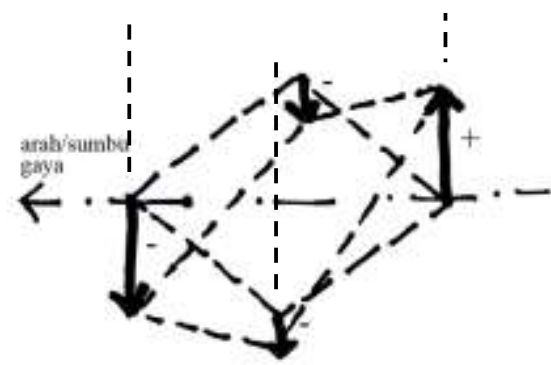

Gambar 11b. Distribusi gaya aksial pada batang vertikal vierendeel terhadap gaya lateral arah diagonal 
Sedangkan struktur Cholla cactus kinerjanya relatif sama terhadap gaya lateral arah sumbu manapun. Struktur Cholla cactus pada dasarnya adalah struktur tabung rangka (frame tube) dengan grid diagonal. Menurut Taranath (2012), pada struktur tabung berbentuk prisma segi empat, sisi yang tegaklurus arah gaya lateral disebut flens dan sisi yang sejajar arah gaya lateral disebut web. Web struktur tabung rangka bekerja dengan aksi rangka pemikul momen menahan gaya geser lateral, sedangkan momen lentur ditahan oleh gaya-gaya aksial yang bekerja di kolom-kolom flens, yaitu gaya aksial tarik disisi sisi bekerjanya gaya lateral dan gaya aksial tekan di sisi yang lain. Karena bentuknya silinder, maka kinerja struktur Cholla cactus lebih menyatu, tidak jelas pemisahan antara flens dan web. Dengan mengasumsikan shear-lag diabaikan, Taranath menampilkan diagram distribusi gaya aksial di semua kolom-kolom perimeter pada struktur tabung rangka berbentuk silinder (Gambar 12). Pada struktur tabung rangka berbentuk silinder, perilaku tersebut berlaku untuk semua arah gaya lateral.

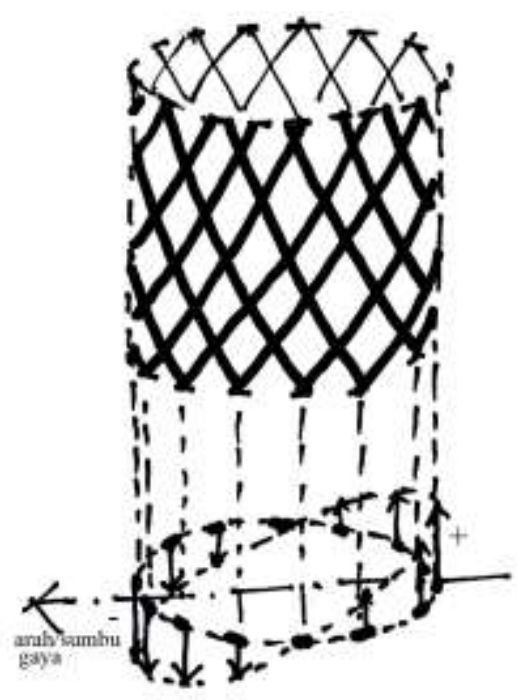

Sumber: diadaptasi dari Taranath, 2012

Gambar 12. Distribusi gaya aksial pada serat-serat dinding Cholla cactus

Dengan kinerja seperti diuraikan diatas, maka problem tekuk perlu dikaji pada kedua model struktur. Struktur bell tower maupun Cholla cactus tidak memliliki sekat-sekat/bidang-bidang diafragma melintang yang dapat membagi seluruh tinggi struktur menjadi beberapa bagian untuk membagi-bagi panjang tekuk. Pada struktur bell tower, panjang tekuk arah sumbu $\mathrm{x}$ dan sumbu y tiap kolom bell tower terbagi-bagi oleh batang-batang horisontal vierendeel tiap 2 meter sehingga tekuk seluruh tinggi kolom bell tower didukung oleh seluruh sistem struktur sebagai satu kesatuan, sedangkan panjang tekuk lokal kolom adalah 2 meter. Sedangkan pada rangka-bidang perimeter Cholla cactus, panjang tekuk arah sumbu radial adalah seluruh tinggi struktur, tekuk tersebut ditahan bersama-sama oleh serat-serat yang saling terangkai satu sama lain yang membentuk 'bidang' silinder, sedangkan panjang tekuk lokal tiap serat arah perimeter adalah sepanjang jarak antar serat.

Maka dapat disimpulkan bahwa efisiensi struktur bell tower lebih cenderung diinspirasi oleh 'model/ sistem' struktur Cholla cactus daripada bentuknya, namun implementasinya berbeda. Model struktur Cholla cactus tersebut dikembangkan sesuai kebutuhan, sehingga kinerja struktur bell tower dan struktur Cholla cactus secara keseluruhan berbeda. Struktur bell tower termasuk efisien karena penampang melintangnya berongga, dan 'bidang' perimeternya juga merupakan 'bidang' berongga, yaitu struktur vierendeel. Dalam kasus ini Frei Otto menunjukkan ketajaman intuisinya melihat kelebihan model/sistem struktur Cholla cactus dan kemampuannya mengiplementasikan dalam desain struktur bangunan.

\section{Struktur Kolom Bercabang.}

Struktur kolom bercabang berbentuk menyerupai pohon (Gambar 13), adalah salah satu alternatif struktur untuk memecahkan bentang lebar yang distudi oleh Frei Otto (1960) dan beberapa peneliti lain seperti Marek Kolodziejczyk, Kai-Uwe Bletzinger, Peter von Beulow, Flamur Ahmeti (2007). Bentuk kolom bercabang menyerupai pohon, yaitu ada batang utama yang tertanam di pondasi, batang utama tersebut menahan cabang-cabang diagonal dan puncaknya menumpu balok-balok atap dengan join sendi. Pada dasarnya struktur kolom bercabang merupakan struktur semi form-active, karena didalam batang dan cabang-cabangnya bekerja momen dan gaya asial tekan. Bentuknya yang menyerupai pohon menguntungkan karena sistem tersebut mempunyai batang yang pendek-pendek sehingga jarak antara titik pembebanan dengan penumpunya pendek (Ahmeti, 2007), dengan demikian panjang tekuknya relatif kecil

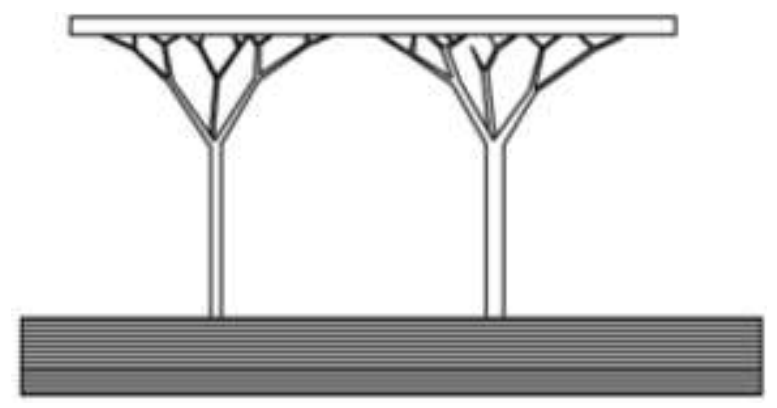

Sumber: Ahmeti, 2007

Gambar 13. Model Struktur Kolom Bercabang Sketsa Frei Otto. 
Menurut Roland (1970) penelitian-penelitian yang pernah dilakukan bertujuan untuk menemukan kompromi optimal antara jumlah batang tekan, atau titik penumpu, dan panjang tekuk agar volume materialnya minimal. Beulow (2007) melakukan pencarian bentuk dengan program komputer Intelligent Genetic Design Tool (IGDT) dan menggunakan Genetic Algorithms (GA's) untuk optimasi geometri dan topologi struktur. Disimpulkannya bahwa terhadap beban yang berat lebih efisien batang yang lebih panjang, sedangkan terhadap beban yang ringan lebih efisien batang yang lebih pendek. Hal ini disebabkan karena terhadap beban tekan besar kekuatan batang lebih dominan menentukan dimensi penampang melintang, sedangkan terhadap beban tekan ringan kekakuan tekuk batang lebih dominan menentukan dimensi penampang melintang. Flamur Ahmeti (2007) dengan program komputer BUILD melakukan simulasi struktur kolom bercabang pada bangunan-bangunan: Stuttgart Airport, Germany; Beaverton Library, Oregon, USA; Therme Bad Oeynhausen, Germany. Material konstruksi yang disimulasikan adalah baja, kayu solid dan gluelaminated wood (tappered). Dari segi material tersebut, simulasi dari semua studi kasus menunjukkan bahwa material baja mempunyai kapasitas dukung beban paling tinggi dengan volume dan berat material paling kecil.

\section{Diskusi:}

Kolom bercabang yang dibahas tersebut bentuk dan susunan batang/cabang-cabangnya menyerupai bentuk dan susunan batang dan cabang-cabang pohon. Ada perbedaan model struktur kolom bercabang yang sangat berpengaruh terhadap kinerja struktur dengan model struktur pohon, bandingkan Gambar 13 dan Gambar 14. Dengan model sederhana dapat dipelajari perilaku gaya pada model struktur kolom bercabang dan model struktur pohon (Gambar 15a, 15b). Terhadap beban terpusat di ujung cabang (tanpa berat sendiri), model struktur kolom bercabang mendukung momen kantilever dengan gaya tarik di batang horisontal atas (balok atap/D3) dan kombinasi gaya tekan, momen lentur, gaya geser di cabangcabang miring (D2); sedangkan model struktur pohon (tanpa berat sendiri) mendukung momen kantilever dengan kombinasi momen lentur, gaya geser dan gaya tekan oleh masing-masing cabang D5. Walaupun model struktur kolom bercabang berbentuk truss, tapi pada cabang-cabang miring juga bekerja momen negatif (maksimal di pangkal cabang-cabang miring D2), hal ini disebabkan join pertemuan antar cabangcabang D2 dan dengan batang utama D1 adalah join kaku untuk mendapatkan stabilitas struktur. Pada cabang D2 dan D5, masing-masing bekerja gaya aksial tekan dan momen, dari Tabel 1 nampak bahwa model struktur kolom bercabang didominasi gaya aksial tekan, sedangkan model strukttur kantilever didominasi momen. Melalui simulasi Stuttgart Airport, Ahmeti (2007) membandingkan efisiensi model struktur kolom bercabang dengan model struktur pohon, dia menemukan bahwa model struktur kolom bercabang mereduksi deformasi $60 \%$ dibandingkan dengan model struktur pohon alami.

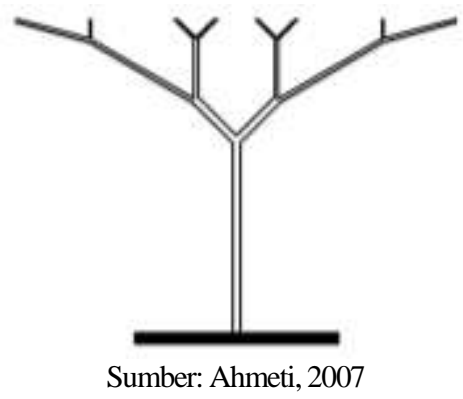

Gambar 14. Model Struktur Pohon.

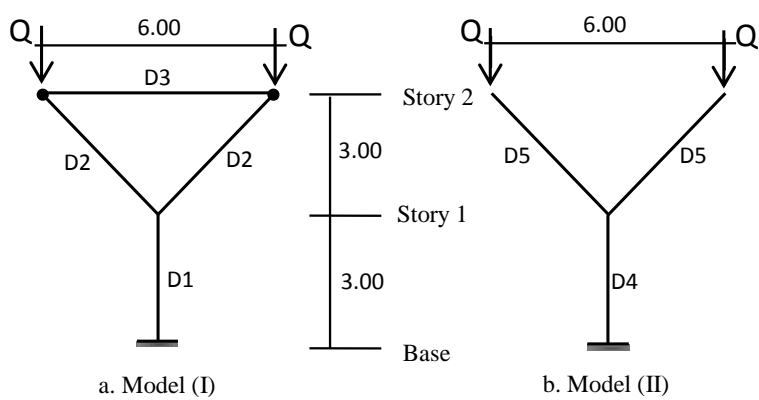

Catatan: $\mathrm{Q}=1000 \mathrm{~kg}$, diameter $\mathrm{D} 1=\mathrm{D} 4=20 \mathrm{~cm}$, dimeter $\mathrm{D} 2=\mathrm{D} 3=\mathrm{D} 5=20 \mathrm{~cm}$

Gambar 15. Model Struktur Kolom Bercabang dan Model Struktur Pohon

Tabel 1. Perbandingan Besarnya Momen dan Gaya Aksial pada Model Struktur kolom Bercabang dengan Model Struktur Pohon

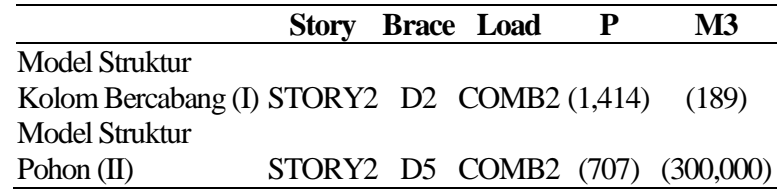

Maka dapat disimpulkan bahwa efisiensi dari model/sistem struktur kolom bercabang tidak diperoleh dari model/sistem struktur pohon. Frei Otto tidak memanfaatkan 'model struktur' pohon, tetapi lebih memanfaatkan 'bentuk' pohon yang terdiri dari susunan cabang-cabang pendek berbentuk truss. 
Struktur kolom bercabang termasuk struktur semi form-active yang efisien karena gaya aksial tekan lebih dominan bekerja di batang/cabangcabangnya, dan panjang tekuk batang/cabangcabangnya pendek. Dalam kasus ini Frei Otto menunjukkan ketajaman intuisinya melihat kelebihan bentuk dan susunan dari pohon, dengan merubah model/sistem strukturnya diperoleh sistem struktur yang efisien.

\section{KESIMPULAN}

Untuk memanfaatkan prinsip efisiensi bendabenda/mahluk-mahluk alami sebagai inspirasi desain diperlukan kejelian, intuisi, kreatifitas dan penguasaan prinsip struktur bangunan yang memadai. bahwa:

Dari tiga studi kasus yang dibahas, ditemukan

- Benda/mahluk alami apa saja memungkinkan untuk digali potensinya, bahkan dari yang sangat kecil dimensinya untuk dikembangkan menjadi struktur bangunan yang efisien.

- Tidak semua benda alami dapat mentah-mentah dimanfaatkan model/sistem strukturnya untuk menghasilkan struktur yang efisien, perlu kreatifitas untuk mengembangkan atau memodifikasi bentuknya sehingga menjadi sistem yang efisien.

- Benda/mahluk alami yang berbentuk form-active, baik 'model/sistem struktur'nya maupun 'bentuk'nya dapat dikembangkan dalam desain bangunan menjadi sistem struktur yang sangat efisien.

- Benda/mahluk alami yang berbentuk non formactive dan semi form-active perlu pengembangan lebih lanjut agar sesuai dengan kebutuhan bangunan. Pengembangan tersebut bisa dilakukan pada model/sistem strukturnya (seperti kasus bell tower), bisa bentuknya (seperti kasus kolom bercabang).

\section{DAFTAR PUSTAKA}

Ahmeti, F. (2007). Efficiency of lihgt weight structural form: the case of tree like structure-a comparative structural analysis, Continuing Education Centre TU Vienna. from http://publik. tuwien.ac.at/files/pub-ar_7968.pdf.

Engel, H. (1977). Structure system, Suttgart: Deutsche Verlags-Anstalt GmbH.

Howard, S. (1966). Structure an architec's approach, New York: Mc Graw-Hill.

Lim, J. (2009). Bio-structural analogues in architectture, Singapore: Page One Publishing Pte Ltd.

Macdonald, Angus (2001). Struktur dan arsitektur, (Priatmono \& Ajie, P. H), Jakarta: Erlangga.

Munson, B. L. (2003). Mekanika Fluida jilid 4, (Harinaldi \& Budiarso), Erlangga.

Roland (1970). Frei Otto - structures, London: Longman.

Sandaker, B. N. (2008). On span and space, New York: Routledge.

Taranath, B. S. (2012). Structural analysis and design of tall buildings, London: Boca Raton.

Von Buelow, P. (2007). A geometric comparison of Brancing Structures in tension and compression versus minimal path, from http://deepblue.lib. umich.edu/bitstream/2027.42/58599/1/pvb_IA SS07.pdf.

Wiliams, H. A. (2003). Zoomorphic, new animal architecture, Laurence King Publishing, London UK. 